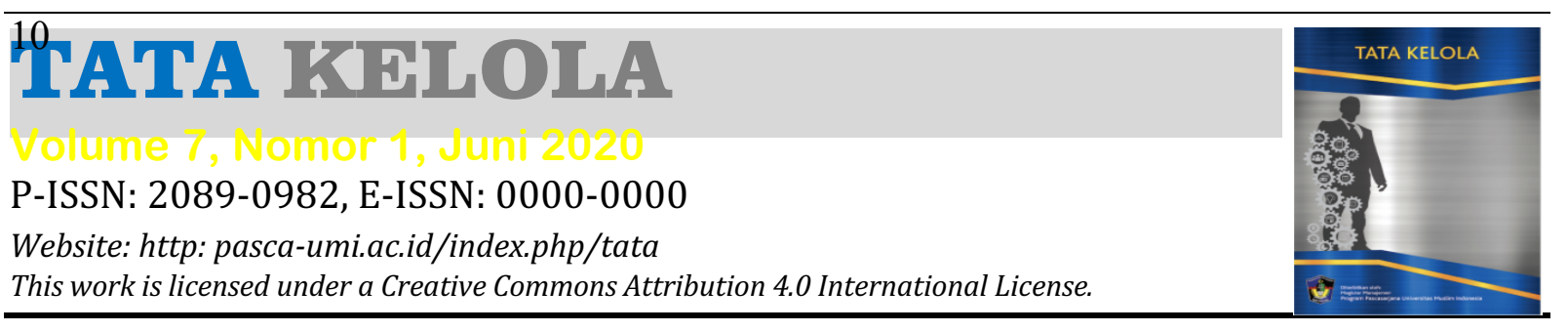

\title{
Pengaruh Motivasi, Kompetensi, dan Lingkungan Kerja terhadap Kinerja Pegawai
}

\author{
Kariyamin $^{1}$, Nasir Hamzah², Niniek Lantara ${ }^{3}$ \\ 12,3, Magister Manajemen, Universitas Muslim Indonesia. \\ ${ }_{1}^{1}$ Koresponden Penulis, E-mail: karyaminyamin28@gmail.com
}

\begin{abstract}
ABSTRAK
Penelitian ini bertujuan untuk menguji sejauh mana pengaruh motivasi, kompetensi, dan lingkungan kerja terhadap kinerja pegawai Badan Pengelola Pajak dan Retribusi Daerah Kota Kendari Sulaweis Tenggara. Pengumpulan data dilakukan melalui penyebaran kuesioner dan dilaksanakan pada 33 pegawai Badan Pengelola Pajak dan Retribusi Daerah Kota Kendari Sulaweis Tenggara. Analisis data pada penelitian ini menggunakan bantuan program SPSS versi 24. Teknik sampling yang dipakai adalah metode sensus dan teknik pengujian data yang digunakan dalam penelitian ini meliputi Uji asumsi klasik dan analisis regresi linier berganda, untuk menguji dan membuktikan hipotesis penelitian. Hasil analisis menunjukkan bahwa secara simultan motivasi, kompetensi, dan lingkungan kerja berpengaruh terhadap kinerja pegawai dan secara parsial yang berpengaruh dominan terhadap kinerja pegawai adalah motivasi.
\end{abstract}

Kata Kunci: Motivasi; Kompetensi; Lingkungan Kerja

\begin{abstract}
This study aims to examine the extent of the influence of motivation, competence and work environment on the performance of employees of the Southeast Sulawesi Sulaweis City Kendari Management and Retribution Agency. Data collection was carried out through questionnaires and was carried out on 33 employees of the Southeast Sulawesi Sulaweis City Regional Tax and Retribution Management Agency. Data analysis in this study used SPSS version 24. The sampling technique used was the census method and data testing techniques used in this study include the classic assumption test and multiple linear regression analysis, to test and prove the research hypothesis. The analysis shows that simultaneous motivation, competence, and work environment influence employee performance and partially the dominant influence on employee performance is motivation.
\end{abstract}

Keyword: Motivation; Competence; Work Environment 


\section{PENDAHULUAN}

Sumber daya manusia merupakan salah satu unsur dari organisasi dan mempunyai peranan yang penting dalam kegiatan organisasi. (Nitisemito, 2011) mengemukakan bahwa manusia sebagai salah satu komponen organisasi merupakan sumber daya penentu tercapainya visi dan misi organisasi. Organisasi merupakan suatu sistem yaitu rangkaian dan hubungan antar bagian komponen yang bekerja sama secara keseluruhan. Terdapat hubungan yang erat antara kinerja perseorangan dengan kinerja organisasi, bila kinerja baik maka kinerja organisasi juga baik (Nitisemito, 2011).

Kinerja merupakan hasil kerja yang dapat dicapai oleh seseorang atau sekelompok orang dalam suatu organisasi, sesuai dengan wewenang dan tanggung jawab masing masing, dalam rangka upaya mencapai tujuan organisasi bersangkutan secara legal, tidak melanggar hukum dan sesuai dengan moral maupun etika (Simamora, 2012). Menurut (Mangkunegara, 2012), kinerja pegawai (prestasi kerja) adalah hasil kerja secara kualitas dan kuantitas yang dicapai oleh seseorang pegawai dalam melaksanakan tugasnya sesuai dengan tanggung jawab yang diberikan kepadanya.

Banyak sekali faktor yang mempengaruhi kinerja seorang pegawai, baik yang berasal dari pegawai itu sendiri atau dari luar diri pegawai tersebut. Faktor yang berasal dari diri pegawai adalah faktor-faktor internal yang meliputi kompetensi berdasarkan pengetahuan dan keterampilan, motivasi kerja, kepuasan kerja dan gaya kepemimpinan. Sedangkan faktor dari luar diri pegawai meliputi lingkungan kerja dan situasi kerja (Wibowo, 2013), beberapa di antara faktor yang mempengaruhi kinerja pegawai antara lain adalah motivasi, kompetensi dan lingkungan kerja pegawai.

Motivasi merupakan sesuatu yang menimbulkan semangat atau dorongan kerja. Dalam kinerja pegawai agar seseorang lebih semangat lagi perlu adanya motivasi dalam bekerja. Tetapi motivasi bukan merupakan satu-satunya agar kinerja pegawai baik. Dengan adanya motivasi, maka terjadilah kemauan kerja dan dengan adanya kemauan untuk bekerja serta dengan adanya kerja sama, maka kinerja akan meningkat. Motivasi adalah suatu faktor yang mendorong seseorang untuk melakukan suatu aktivitas tertentu, oleh karena itu motivasi sering kali diartikan pula sebagai faktor pendorong perilaku seseorang (Wursanto,2010); (Mangkunegara, 2012). Hasil penelitian yang dilakukan oleh (Nurhaedah, 2018), menunjukkan bahwa kemampuan kerja dan motivasi kerja berpengaruh positif dan signifikan terhadap kinerja karyawan PT. Semen Tonasa Kabupaten Pangkep.

Kompetensi pegawai adalah kemampuan dan karakteristik yang dimiliki oleh seorang pegawai berupa pengetahuan, keahlian dan sikap perilaku yang diperlukan dalam pelaksanaan tugas jabatannya. Menurut (Wiibowo, 2010), untuk mencapai suatu kompetensi, seseorang perlu memiliki sejumlah kapabilitas yang merupakan kombinasi dimensi sifat pengetahuan, keterampilan dan sikap (sifat pribadi). Kompetensi seseorang termasuk kategori tinggi atau baik ditunjukkan apabila sudah melakukan pekerjaan, sebaliknya apabila mempunyai kompetensi tingkat rendah cenderung berkinerja rendah pula.

Kondisi kerja pegawai pada Badan Pengelola Pajak dan Retribusi Daerah (BPPRD) kota Kendari Sulawesi Tenggara belum tertanamnya jiwa untuk melaksanakan 
tugasnya dengan inisiatif sendiri, pegawai melaksanakan tugasnya dengan diperintah terlebih dahulu dari atasan, pegawai itu sendiri baru mau bekerja. Hal ini mengakibatkan standar kerja yang kurang efektif belum maksimal tercapai. Potensi yang dimiliki pegawai pada BPPRD kota Kendari Sulawesi Tenggara belum dapat menemukan standar kerja yang baik dikarenakan masih kurangnya fasilitas kerja yang mendukung para pegawai untuk menyalurkan kemampuannya. Hal ini menjadi hambatan para pegawai dalam bekerja untuk menghasilkan kinerja yang baik. Selanjutnya peran atasan dalam mempengaruhi kinerja pegawai dalam rangka mencapai tujuan organisasi belum dapat terpenuhi, karena kurangnya komunikasi antara atasan dengan bawahannya. Hasil penelitian yang dilakukan oleh (Iswahyudi, 2015) menemukan bahwa kompetensi berpengaruh positif dan signifikan terhadap kinerja pegawai pada kantor Walikota Palopo. Kondisi nyata yang terjadi di BPPRS Kota Kendari, utamanya kinerja aparatur pelaksanaannya belum menunjukkan kinerja yang optimal yang tercermin dari data berikut ini:

Tabel 1: Daftar Penerimaan PAD kantor BPPRD Kota Kendari Provinsi Sulawesi Tenggara Tahun 2016-2018

\begin{tabular}{clcrc}
\hline No & Tahun & Target (Rp) & Realisasi (Rp) & Persentase \\
\hline 1 & 2016 & $269,064,250,823.00$ & $170,624,038,880.64$ & $63,41 \%$ \\
2 & 2017 & $284,968,935,797.00$ & $179,062,775,226.99$ & $62,84 \%$ \\
3 & 2018 & $408,475,410,745.00$ & $218,340,628,965.02$ & $53,45 \%$ \\
\hline
\end{tabular}

Sumber :Kantor BPPRD Kota Kendari

Dalam kaitannya dengan kinerja pegawai, hal tersebut tentunya harus segera dibenahi agar para pimpinan dan bawahan pada BPPRD dapat memberikan pelayanan yang prima kepada masyarakat secara lebih profesional.Penelitian ini dilakukan untuk mengetahui apakah motivasi, kompetensi dan lingkungan kerja mempunyai pengaruh signifikan terhadap kinerja pegawai dalam suatu organisasi pemerintah. Berdasarkan fenomena di atas dan penelitian terdahulu, maka akan dilakukan penelitian dengan judul "Pengaruh Motivasi, Kompetensi dan Lingkungan Kerja Terhadap Kinerja Pegawai pada Kantor Badan Pengelola Pajak dan Retribusi Daerah (BPPRD) kota Kendari Sulawesi Tenggara".

Berdasarkan uraian tersebut, maka kerangka konseptual penelitian ini adalah:

Gambar 1: Kerangka Konseptual Penelitian

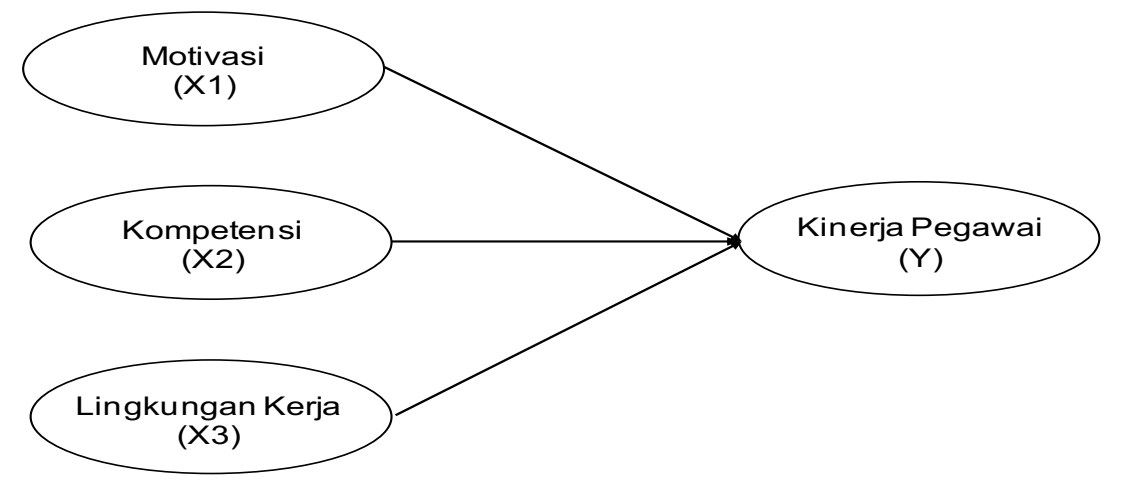


Hipotesis 1: Motivasi berpengaruh signifikan terhadap kinerja pada Kantor Badan Pengelola Pajak dan Distribusi Daerah (BPPRD) Kota Kendari Sulaewesi Tenggara.

Hipotesis 2: Kompetensi berpengaruh signifikan terhadap kinerja pada Kantor Badan Pengelola Pajak dan Distribusi Daerah (BPPRD) Kota Kendari Sulaewesi Tenggara.

Hipotesis 3: Lingkungan Kerja berpengaruh signifikan terhadap kinerja pada Kantor Badan Pengelola Pajak dan Distribusi Daerah (BPPRD) Kota Kendari Sulaewesi Tenggara.

\section{METODE PENELITIAN}

Penelitian dilakukan pada Kantor Kantor Badan Pengelola Pajak Dan Retribusi Daerah (BPPRD) kota Kendari Sulawesi Tenggara dengan jumlah populasi sebanyak 33 orang. Penentuan sampel dalam penelitian ini menggunakan metode sensus karena jumlah populasi yang kurang dari 100 (Sugiyono, 2013). Pengumpulan data penelitian dilakukan dengan mendatangi langsung lokasi penelitian untuk mendapatkan data primer melalui penyebaran kuesioner kepada responden. Metode analisis data yang digunakan untuk mengolah data serta menarik kesimpulan penelitian ini dibantu dengan program SPSS versi 24. Data yang berhasil dikumpulkan akan dianalisis dengan beberapa tahap pengujian yaitu uji statistic deskriptif, uji asumsi klasik (Uji normalitas, multikolinearitas, heterokedastisitas) dan pengujian hipotesis dengan pengujian regresi berganda, uji $F$, uji parsial ( $t$ ) dan uji koefisien determinasi.

Untuk menjawab hipotesisi penelitian maka digunakan rumus menggunakan analisis regresi berganda sebagai berikut:

$\mathrm{Y}=\mathrm{a}+\beta 1 \mathrm{X} 1+\beta 2 \mathrm{X} 2+\beta 3 \mathrm{X} 3+\mathrm{e}$

Keterangan:

$\mathrm{Y} \quad=$ Kinerja Pegawai

a $\quad=$ Konstanta

$\beta 1-\beta 3=$ Koefisien Regresi

$\mathrm{X} 1 \quad=$ Motivasi

$\mathrm{X} 2=$ Kompetensi

X3 = Lingkungan Kerja

e $\quad=$ Error estimate

\section{HASIL PENELITIAN DAN PEMBAHASAN}

\section{Hasil}

Berdasarkan data yang diperoleh dari lokasi penelitian, hasil olahan data statistic dari SPSS adalah Hasil analisis uji validasi instrumen variabel motivasi, kompetensi lingkungan kerja dan kinerja pegawai diperoleh nilai Corrected item total correlation 
( $\mathrm{r}$ hitung) $>\mathrm{r}$ tabel 0,2609, artinya setiap butir pernyataan dari variabel yang digunakan dalam penelitian adalah valid. Sedangkan, pengujian reliabilitas variabel motivasi, kompetensi, lingkungan kerja, dan kinerja pegawai, ternyatadiperoleh nilai Cronbach Alpha $\geq 0,60$. Dengan demikian, maka hasil ujirelibilitas terhadap keseluruhan variabel adalah reliabel.

Nilai F hitung pada tabel 2 menunjukkan nilai yang lebih besar dari nilai $\mathrm{F}$ tabel maka disimpulkan bahwa secara bersama-sama motivasi (X1), kompetensi (X2) danlingkungan kerja(X3) berpengaruh secara simultan dan signifikan terhadap kinerja pegawai padaBadan Pengelola Pajak dan Retribusi Daerah (BPPRD) kota Kendari Sulawesi Tenggara.

Tabel 2: Uji F (Simultan)

\begin{tabular}{|c|c|c|c|c|c|c|}
\hline & del & $\begin{array}{l}\text { Sum of } \\
\text { Squares }\end{array}$ & $\mathrm{df}$ & $\begin{array}{l}\text { Mean } \\
\text { Square }\end{array}$ & $\mathrm{F}$ & Sig. \\
\hline \multirow[t]{3}{*}{1} & Regression & 1.271 & 3 & .424 & 30.544 & $.000^{\mathrm{a}}$ \\
\hline & Residual & .389 & 28 & .014 & & \\
\hline & Total & 1.660 & 31 & & & \\
\hline
\end{tabular}

a. Predictors: (Constant), Lingkungan Kerja, Kompetensi, Motivasi

b. Dependent Variable: Kinerja Pegawai

Sumber : Hasil Analisis Data 2020

Untuk mengetahui besarnya pengaruh masing-masing variabel independen(X1, $\mathrm{X} 2$, X3) terhadap variabel dependen (kinerja pegawai) secara parsial, dapat dilakukan dengan membandingkan nilai t-hitung $>$ t-tabel $(2,048)$ dan $\alpha<0,05$ pada tabel 3 .

Tabel 3: Uji t (Parsial)

\begin{tabular}{|c|c|c|c|c|c|}
\hline \multirow[b]{2}{*}{ Model } & \multicolumn{2}{|c|}{$\begin{array}{l}\text { Unstandardized } \\
\text { Coefficients }\end{array}$} & \multirow{2}{*}{$\begin{array}{c}\text { Standardized } \\
\text { Coefficients } \\
\text { Beta }\end{array}$} & \multirow[b]{2}{*}{$t$} & \multirow[b]{2}{*}{ Sig. } \\
\hline & B & Std. Error & & & \\
\hline 1 (Constant) & .773 & .370 & & 2.087 & .046 \\
\hline Motivasi & .325 & .125 & .390 & 2.597 & .015 \\
\hline Kompetensi & .206 & .088 & .298 & 2.332 & .027 \\
\hline Lingkungan Kerja & 285 & .127 & 301 & 2.244 & .033 \\
\hline
\end{tabular}

a. Dependent Variable: Kinerja Pegawai

Sumber: Data diolah 2020

Hasil pengujian determinasi (R2) adalah 0,766. Nilai tersebut menunjukkan bahwa kontribusi variabel independen yaitu motivasi, kompetensidan lingkungan kerja terhadap variabel dependen yaitu kinerja pegawai padaBadan Pengelola Pajak dan Retribusi Daerah (BPPRD) kota Kendari Sulawesi Tenggara adalah sebesar 76,6 persen, sedangkan sisanya $23,4 \%$ persen ditentukan oleh faktor lain yang tidak dimasukkan dalam penelitian ini. 
Tabel 4: Nilai Koefisien Determinasi $\left(\mathrm{R}^{2}\right)$

\begin{tabular}{|c|c|c|c|c|}
\hline Model & $\mathrm{R}$ & R Square & $\begin{array}{l}\text { Adjusted R } \\
\text { Square }\end{array}$ & $\begin{array}{l}\text { Std. Error of the } \\
\text { Estimate }\end{array}$ \\
\hline 1 & $.875^{\mathrm{a}}$ & .766 & .741 & .11780 \\
\hline
\end{tabular}

\section{Pembahasan}

\section{Pengaruh Motivasi Kerja terhadap Kinerja Pegawai}

Motivasi berpengaruh terhadap kinerja karena motivasi akan dapat mendorong pegawai untuk melaksanakan pekerjaan sebaik mugkin, dalam artian bahwa semakin tinggi motivasi seorang pegawai maka akan semakin tinggi pula kinerja pegawai yang bersangkutan.Artinya, para pegawai yang memiliki motivasi kerja tinggi akan cenderung memiliki tingkat kinerja yang tinggi. Sebaliknya, pegawai yang motivasi berprestasinya rendah kemungkinan akan memperoleh kinerja yang rendah.Proses motivasikerja yang menunjukkan kebutuhanyang tidak terpuaskan akan meningkatkantegangan dan memberikan dorongan padapegawai dan menimbulkan perilaku.Pada Badan pengelola Pajak dan Retribusi Daerah (BPPRD) kota Kendari Sulawesi Tenggara tanpa ada motivasi sukar untukberhasil, pegawai dalam tugas melaksanakantugas pimpinanBadan pengelola Pajak dan Retribusi Daerah (BPPRD) kota Kendari Sulawesi Tenggara memerlukan motivasi baik dari faktor eksternalmaupun internal. Motivasi pegawai di Badan pengelola Pajak dan Retribusi Daerah (BPPRD) kotaKendari Sulawesi Tenggaradalam bekerja dapat berupa intensitas(kesungguhan dan ketekunan) yang tinggi dalammelaksanakan tugas.

Hasil uji secara parsial (Uji t) dapat diketahui bahwa variabel motivasi kerja berpengaruh positif dan signifikan terhadap kinerja pegawai pada pada Badan Pengelola Pajak dan Retribusi Daerah (BPPRD) Kota Kendari Suawesi Tenggara. Hal ini mengindikasikan hubungan yang searah antara motivasi dengan kinerja pegawai, dalam arti jika motivasi pegawai ditingkatkan maka kinerja pegawai juga meningkat. Dari hasil penelitian ini menunjukkan bahwa pegawai yang ada telah mampu menyelesaikan pekerjaannya dengan baik sesuai dengan waktu yang telah ditentukan serta mampu memenuhi harapan dari pimpinannya. Pekerjaan yang ada memang relatif dapat dikerjakan secara bersama dengan bantuan masing-masing bidang yang dibentuk didalam tim kerja ataupun berdasarkan hasil komunikasi aktif yang dilakukan oleh mereka yang berkerja di Hasil uji secara parsial (Uji t) dapat diketahui bahwa variabel motivasi kerja berpengaruh positif dan signifikan terhadap kinerja pegawai padapada Badan Pengelola Pajak dan Retribusi Daerah (BPPRD) Kota Kendari Suawesi Tenggara. Hal ini mengindikasikan hubungan yang searah antara motivasi dengan kinerja pegawai, dalam arti jika motivasi pegawai ditingkatkan maka kinerja pegawai juga meningkat. Para pegawai Badan Pengelola Pajak dan Retribusi Daerah (BPPRD) Kota Kendari Suawesi Tenggaramelakukan pekerjaannya berdasarkan atas inisiatif mereka sendiri, serta mereka yang ada rela 
untuk melakukan pekerjaan yang melebihi standar yang ditentukan oleh Badan Pengelola Pajak dan Retribusi Daerah (BPPRD) Kota Kendari Suawesi Tenggaraseperti melakukan pengecekan ulang terhadap pekerjaan yang telah dilakukan dan lain sebagainya.

Penelitian (Nurasiah, 2018); (Riyanto, 2015); (Subakti, 2013), yang menemukan bahwa motivasi berpengaruh signifikan terhadap peningkatan kinerja pegawai. Hasil penelitian ini didukung oleh penelitian yang dilakukan oleh (Ramadhan dan Arifin, 2017) yang menemukan bahwa motivasi berpengaruh positif dan signifikan terhada kinerja pegawai pada Badan Pengelolaan Keuangan dan Aset Daerah Kabupaten Malang.

\section{Pengaruh Kompetensi terhadap Kinerja Pegawai}

Hasil penelitian menunjukkan bahwa variabel kompetensi berpengaruh terhadap kinerja pegawai pada Badan Pengelola Pajak dan Retribusi Daerah (BPPRD) Kota Kendari Sulawesi Tenggara. Artinya jika kompetensi ditingkatkan maka kinerja juga meningkat.

Selanjutnya, hasil tersebut juga memiliki hasil yang sama dengan penelitian terdahulu yang dilakukan oleh (Silfana Nurasiah, 2018), menunjukkan bahwa variabel kompetensi berpengaruhsiginifikan terhadap kinerja pegawai. Demikian juga penelitian yang dilakukan oleh (Nurhaedah, 2018); (Haryanto, 2010); menemukan bahwa kompetensi berpengaruh positif dan signifikan terhadap kinerja pegawai.

\section{Pengaruh Lingkungan Kerja terhadap Kinerja Pegawai}

Hasil pengujian lingkungan kerja terhadap kinerja pegawai Badan Pengelola Pajak dan Retribusi Daerah (BPPRD) Kota Kendari Sulawesi Tenggara adalah berpengaruh positif dan signifikan, hal ini menunjukan bahwa apabila semakin baik lingkungan kerja, maka akan mempengaruhi kinerja pegawai. Badan Pengelola Pajak dan Retribusi Daerah (BPPRD) Kota Kendari Sulawesi Tenggara menyediakan lingkungan kerja yang memadai bagi pegawainya seperti penerangan/cahaya yang cukup, sirkulasi udara diruangan, ruang kerja yang sejuk, keamanan di tempat kerja dan hubungan kerja yang baik sesama pegawai. Hal ini menunjukkan bahwa dengan adanya lingkungan kerja yang kondusif telah dapat memberikan peningkatan terhadap aktivitas kerja pegawai dengan baik. Banyak dari pegawai yang aktif untuk tetap berkerja di dalam ruangannya untuk menyelesaikan tugas-tugas yang telah diberikan.

Hasil penelitian ini sesuai dengan pendapat yang dikemukakan oleh (Davis, 1981) dalam (Sumantri, 2016) yang menyatakan bahwa lingkungan kerja dalam suatu organisasi mempunyai arti penting bagi individu yang bekerja di dalamnya, karena lingkungan kerja akan berpengaruh secara langsung maupun tidak langsung terhadap manusia yang ada didalamnya. Beberapa faktor perlu diperhatikan dalam kaitannya dengan kondisi kerja antara lain, tersedianya fasilitas yang memadai, ruang kerja yang bersih dan kantor yang bergengsi (Sofyan, 2013); (Kartini, 2017); 
(Norianggono, 2014). Kebijakan organisasional bukan hanya bermanfaat pada satu pihak, perusahaan akan mendapatkan suatu sistem dalam mengelola karyawan secara berkesinambungan, walaupun awalnya mengeluarkan dana relatif besar. Pada pihak lain, para karyawan akan memperoleh hasil dalam pengembangan dirinya, sehingga dapat meningkatkan prestasi kerjanya yang pada akhirnya berpengaruh pada peningkatan kinerja perusahaan juga.

\section{KESIMPULAN}

Hasil penelitian ini menemukan bahwa secara parsial maupun simultan variabel motivasi, kompetensi dan lingkungan kerja berpengaruh terhadap kinerja pegawai pada Badan Pengelola Pajak dan Retribusi Daerah (BPPRD). Berdasarkan hasil dari karakterisitk responden dan hasil analisis data pada pengujian hipotesis secara parsial, hasil penelitian ini menyarankan agar Pemerintah Provinsi dan Kepala Badan sebaiknya lebih mendorong peningkatan motivasi, kompetensi, dan keadaan lingkungan kerja agar kinerja para pegawai dalam pelayanan kepegawaian pada Badan Pengelola Pajak dan Retribusi Daerah semakin meningkat, misalnya, melalui pendidikan dan pelatihan, peningkatan insetif, dan bonus kesejahteraan, dan juga melengkapi fasilitas pegawai dalam hal ini adalah sarana dan prasarana. Hasil penelitian ini jga menyarankan kepada peneliti selanjutnya agar dapat menggunakan variabel lain dalam mengukur kinerja pegawai agar wawasan tentang faktor-faktor yang dapat mempengaruhi kinerja pegawai dapat bertambah.

\section{DAFTAR PUSTAKA}

Basalamah, J., Pramukti, A., \& Basalamah, A. (2019). Kemampuan, Komitmen Dan Sarana Prasarana Terhadap Kinerja Pegawai Rumah Sakit. CESJ: Center Of Economic Students Journal, 2(2), 153-164.

Budianto, A. A. T., \& Katini, A. (2017). Pengaruh lingkungan kerja terhadap kinerja pegawai pada PT Perusahaan Gas Negara (PERSERO) Tbk SBU Distribusi wilayah I Jakarta. KREATIF: Jurnal Ilmiah Prodi Manajemen Universitas Pamulang, 3(1).

Iswahyudi. 2014. Pengaruh Motivasi Kerja dan Kompetensi Terhadap Kinerja Pegawai pada Bagian Humas dan Protokol Kota Palopo. Tesis Universitas Muslim Indonesia.

Mangkunegara, 2005.Manajemen Sumber Daya Manusia Perusahaan, Cetakan Kedelapan. Bandung: PT Remaja Rosdakarya.

Mangkunegara, Anwar Prabu , 2012. Evaluasi Kinerja SDM. PT. RefikaAditama, Bandung.

Nitisemito, A. S. (2011). Manajemen Personalia (Manajemen Sumber. DayaManusia, Edisi Kelima, Cetakan KeempatBelas, Ghalia.

Norianggono, Y. C. P. (2014). Pengaruh lingkungan kerja fisik dan non fisik terhadap kinerja karyawan (Studi pada karyawan PT. Telkomsel Area III Jawa-Bali Nusra di Surabaya). Jurnal Administrasi Bisnis, 8(2). 
Nurhaedah, Sukmawati Mardjuni dan H. M Yusuf Saleh. 2018. Pengaruh Kemampuan Kerja dan Motivasi Kerja Terhadap Kinerja Karyawan PT. Semen Tonasa Kabupaten Pangkep. Jurnal Ilmu Administrasi. Vol 7 No 1. Pascasarjana Universitas Bosowa. Makassar.

Pramukti, A. (2019). Pengaruh Motivasi, Kompetensi, dan Pengembangan Karir terhadap Komitmen Organisasi dan Kinerja Pegawai. Celebes Equilibrum Journal, 1(1), 17-23.

Ramadhan, Ridho Hananta dan Arifin, Rois. 2017. Pengaruh Lingkungan Kerja, Motivasi dan Kemampuan Terhadap Kinerja Pegawai (Study Kasus Pada Badan Pengelolaan Keuangan dan Aset Daerah Kabupaten Malang). E-jurnal Riset Manajemen. Fakultas Ekonomi Unisma.

SilfanaNurasiah, 2018. Pengaruh Gaya Kepemimpinan, Motivasi Kerja Dan Kompetensi Terhadap Kinerja Pegawai Pada Kantor Badan Pengelolaan Keuangan Kabupaten Gowa. Tesis. UMI Makassar.

Simamora, Henry. 2012. Manajemen Sumber Daya Manusia. Edisi kedua Sekolah Tinggi IlmuEkonomi (YKPN).Yogyakarta.

Sofyan, D. K. (2013). Pengaruh Lingkungan Kerja Terhadap Kinerja Kerja Pegawai BAPPEDA. Industrial Engineering Journal, 2(1).

Sriwidodo, U., \& Haryanto, A. B. (2010). Pengaruh kompetensi, motivasi, komunikasi dan kesejahteraan Terhadap kinerja pegawai dinas pendidikan. Jurnal Manajemen Sumber Daya Manusia, 4(1), 47-57.

Subakti, A. G. (2013). Pengaruh motivasi, kepuasan, dan sikap kerja terhadap kinerja karyawan di Café X Bogor. Binus Business Review, 4(2), 596-606.

Sugiyono. 2013. Metodologi Penelitian Bisnis. Edisi Kedua. Bandung: Alfabeta

Sumantri, Edi P. 2016. Pengaruh Motivasi Kerja dan Lingkungan Kerja Terhadap Kinerja Karyawan Pada Usaha Penjualan Mobil Bekas di Kecamatan Purwokerto Selatan Kabupaten Banyumas.Jurnal Pro Bisnis. Vol 9 No 2. Universitas Wijayakusuma Purwokerto.

Sutrischastini, A., \& Riyanto, A. (2015). Pengaruh motivasi kerja terhadap kinerja pegawai kantor sekretariat daerah Kabupaten Gunungkidul. Kajian Bisnis Sekolah Tinggi Ilmu Ekonomi Widya Wiwaha, 23(2), 121-137.

Wibowo,2010.Budaya Organisasi (Sebuah Kebutuhan Untuk Meningkatkan Kinerja Jangka Panjang), Cetakan Pertama. Penerbit PT Rajagrafindo Persada, Jakarta.

Wursanto, Ignatius, 2010. Dasar-Dasar Ilmu Organisasi. Penerbit: Andi. Yogyakarta. 